\title{
O ESPETÁCULO CÊNICO "CERIMÔNIA DE ABERTURA DOS JOGOS OLÍMPICOS DE PEQUIM/2008” E SUA RELAÇÃO COM OS VALORES OLÍMPICOS
}

\author{
Débora Regina Primaz: \\ Especialista em Dança pela Pontifícia \\ Unviersidade Católica do Rio Grande do Sul \\ deboraprimaz@hotmail.com \\ Aline Nogueira Haas \\ Professora Adjunta do Curso de Licenciatura em \\ Dança da Universidade Federal do Rio Grande do Sul \\ alinehaas02@hotmail.com \\ Camila Dall'Agnol \\ Especialista em Ciências da \\ Saúde e do Esporte pela PUCRS \\ dallcamila@hotmail.com \\ Nelson Schneider Todt \\ Professor da Faculdade de Educação \\ Física e Ciências do Desporto da PUCRS \\ nelson.todt@pucrs.br
}

RESUMO: Pierre de Coubertin, idealizador dos Jogos Olímpicos da Era Moderna, considerava a Cerimônia de Abertura dos Jogos um meio para ilustrar os valores olímpicos. Os valores olímpicos devem ser representados nas Cerimônias de Abertura por símbolos e ritos e transmitidos na forma de representações coreográficas, dramatúrgicas e culturais. O objetivo desse estudo foi analisar se a Cerimônia de Abertura dos Jogos Olímpicos de Pequim/2008 foi efetiva na transmissão dos valores olímpicos Respeito, Excelência e Amizade. Através da análise do vídeo dessa Cerimônia foi verificado que o espetáculo cênico e as movimentações coreográficas podem auxiliar na transmissão dos valores olímpicos Respeito, Excelência e Amizade.

Palavras-chave: Cerimônias Olímpicas. Valores Olímpicos. Dança. 


\section{Introdução}

A Cerimônia de Abertura dos Jogos Olímpicos mobiliza bilhões de espectadores de todas as regiões do planeta, atraídos pelo seu caráter festivo e simbólico. Trata-se de um marco nos Jogos Olímpicos Modernos, devidamente reconhecido pelo Comitê Olímpico Internacional, em virtude de seu forte viés educacional, sendo capaz de promover os ideais do Olimpismo, em razão de sua magnitude.

Essa Cerimônia deve obedecer a um rigoroso protocolo, que assegura a inclusão dos ideais propostos pelo Olimpismo: Desfile das Delegações participantes, Discurso do Presidente do Comitê Organizador, Abertura Oficial dos Jogos pelo Chefe de Estado, Execução do Hino Olímpico, Entrada e Hasteamento da Bandeira Olímpica, Chegada da Tocha ao Estádio, Acendimento da Pira, Pombos simbolizando a Paz Mundial, Juramento dos Atletas, Juramento dos Árbitros, Hino Nacional do país sede, Programa Artístico (IOC, 2007). Conforme Todt (2009), o modelo de protocolo para os Jogos Olímpicos foi construído ao longo dos anos, após a proposta inicial feita por Pierre de Coubertin em 1894. Sendo assim, a estrutura seguida pelos organizadores dos Jogos Olímpicos é a fusão de elementos que foram sendo inseridos ou eliminados durante estes anos.

Os Jogos Olímpicos de Verão de 2008 (XXIX Olimpíada), ocorreram em Pequim, na República Popular da China, de 8 a 24 de agosto de 2008. Estiveram presentes 204 países, totalizando 10 mil e 500 atletas competindo em 302 eventos dos 28 esportes. O governo chinês investiu mais de US\$42 bilhões no evento, almejando realizar os maiores Jogos Olímpicos da história. A cerimônia de abertura, focada na cultura da China, custou US\$100 milhões e foi assistida por quatro bilhões de pessoas (THE OFFICIAL WEBSITE OF THE BEIJING 2008 OLYMPIC GAMES, 2010).

O espetáculo principal dividiu-se em quatro partes: Cerimônia de boas-vindas, com a chegada do presidente Hu Jintao e a entrada de dois mil e oito percussionistas portando o fous, instrumento tradicional do país; parte artística, apresentada em dois atos: Brilhante Civilização e Era Gloriosa; desfile das delegações, com 204 países participantes; e o encerramento da cerimônia, com os discursos oficiais e o protocolo de abertura dos Jogos, marcado pelo acendimento da Pira Olímpica. 
No programa artístico, apresentado no protocolo da Cerimônia de Abertura dos Jogos Olímpicos de Pequim, verificamos alguns elementos similares aos espetáculos de dança. Em ambos, o material humano aparece como eloqüente entusiasta, sua presença sentimentaliza os atos artísticos, repletos de mensagens implícitas, que se harmonizam com os recursos tecnológicos e geram uma eficaz interatividade entre espetáculo e espectador.

É notória (GARCIA, 2011; MORAGAS, MACALOON e LLINÉS, 1996) a importância que a transmissão da Cerimônia de Abertura dos Jogos Olímpicos passou a ter para a valorização do espírito que irá permear todo o evento. Esse momento tem oportunizado aos anfitriões receber os países participantes, os atletas e toda a audiência, ao cumprir o protocolo exigido e seus significados, fazendo uso de uma das mais complexas e, ao mesmo tempo, simples formas de encantar as pessoas: a imagem:

[...] quando se examina a arte como forma de comunicação, todos os pontos de vista desembocam numa única concepção da arte: um objeto que provoca um prazer estético, que se exprime através da plenitude do sensível e, por isso, comunica emoções, idéias, a atmosfera da época e do meio social. Em outros termos, a arte primeiro se define como expressão, e, na medida em que se realiza como tal, aumenta ou diminui seu poder de comunicação. Primeiro, mostra; depois, diz. (PAVIANI, 2003, p. 56)

Nesse sentido, Pierre de Coubertin, idealizador dos Jogos Olímpicos da Era Moderna, considerava esse momento uma forma ricamente ilustrativa de representar os valores olímpicos, constituídos respectivamente por: Respeito (postura ética perante si e a sociedade), excelência (superação individual, combinando corpo, mente e espírito forte), e amizade (busca pelo entendimento e pela suplantação das diferenças políticas, econômicas, de gênero, de raça ou de religião). Tais valores devem ser expressos no cerimonial de abertura através de símbolos e ritos, e transmitidos através de representações coreográficas, dramatúrgicas e culturais (TODT, 2009).

Considerando a representatividade e o valor histórico do evento, o objeto desse estudo focou-se no espetáculo cênico e nas movimentações coreográficas da "Cerimônia de Abertura dos Jogos Olímpicos de Pequim/2008” e em sua relação com os valores olímpicos. O objetivo, portanto, foi analisar se esse espetáculo foi efetivo na transmissão dos valores olímpicos Respeito, Excelência e Amizade.

Como justificativa à pesquisa, atentamos para os elementos coreográficos, artísticos e 
culturais da solenidade, os quais são entendidos como instrumentos implícitos na promoção dos valores do Olimpismo. A dança, neste contexto, destaca-se como peça-chave na aliança entre cultura e arte, já que as expressões do corpo (coreografia) se integram ao cenário cultural (mensagem) por meio dela.

Dessa forma, o texto será discutido: a partir das considerações teóricas de Pavis (2005), Paviani (2003) e Pesavento (2008) na área das representações; por meio de Garaudy (1976), Mauss (1974), Paludo (2009) e Strazzacappa (1998) nos referenciais para a dança; a partir de Bauer, Gaskell e Allum (2002) na análise metodológica; com base em DaCosta (2009), Müller (2004), Rubio (2009) e Todt (2009) na área dos estudos olímpicos.

\section{Percurso Metodológico}

Esta pesquisa se caracterizou por ser qualitativa e teve como método de coleta de dados a observação de imagens do vídeo da Cerimônia de Abertura dos Jogos Olímpicos de Pequim/2008 (BAUER, GASKELL e ALLUM, 2002).

Loizos (2002) refere que a imagem, com ou sem acompanhamento de som, oferece um registro poderoso, ainda que restrito, das ações temporais e dos acontecimentos reais, tanto nas fotografias quanto nas imagens em movimento.

Após a observação do vídeo, e conforme as fundamentações teóricas selecionadas, buscamos identificar todas as seqüências de ação referentes à parte artística da Cerimônia. Assim, o trecho analisado dividiu-se em dois atos: 'Brilhante Civilização', que contou os 5000 anos de história chinesa, e 'Era Gloriosa', que exibiu as conquistas da China moderna.

A análise dos dados foi feita a partir da união da observação de imagens em movimento, proposta por Bauer, Gaskell e Allum (2002) e através da análise do espetáculo proposta por Pavis (2005).

A descrição do espetáculo cênico da Cerimônia se deu a partir da propriocepção dos pesquisadores. Isso porque, conforme Pavis (2005), o pesquisador não se refere diretamente ao performer, mas à percepção de espectador em relação à identificação de sensações, impulsos e movimentos pelo corpo do atuante. É a cadeia posturo-mimo-gestual que agrupa esse conjunto de dados físicos para, então, se estabelecer a ligação. 
Para entendermos se as movimentações coreográficas da Cerimônia de Abertura dos Jogos Olímpicos de Pequim/2008 auxiliaram na transmissão dos valores propostos pela Educação Olímpica realizamos algumas considerações preliminares, que serão apresentadas a seguir.

Classificamos coreografia ou movimentações coreográficas a partir de uma visão da dança contemporânea, considerando todo movimento que, dentro da parte selecionada para análise, transmitisse qualidades como peso, tempo, espaço e fluxo, podendo haver variação entre quantidade e intensidade, de maneira que as combinações formassem uma seqüência. Para Paludo (2009), a relativização do tempo da performance é instigante. Podemos transportar uma intenção e materializar uma ação, perceber dados momentâneos durante a ação, elaborando um novo significado. Então, o que podemos perceber é sempre o passado, mas que está intrinsecamente conectado com o agora. O passado interfere no presente e o corpo na dança e na performance, sendo um material que pode assumir formas imprevisíveis e temporalidades distintas. O corpo recebe e devolve movimento, na mesma intensidade que o produz. Todos esses elementos apresentados fazem parte de uma concepção maior sobre o que é dança contemporânea e produção contemporânea.

Em relação à expressão valor, com razão DaCosta (2009) ao referir que é designada por Coubertin como sinônimo de princípio, ideia, ideal ou virtude quando da recuperação dos ideais olímpicos gregos. No seu entendimento, o termo valor também pode ser compreendido como "um conjunto de crenças, concepções, sentimentos [...] que traduzem significados da vida cotidiana." (DACOSTA, 2009, p. 20-21). Esses valores, segundo Rubio (2009), norteiam as atitudes e ações que envolvem todas as atividades olímpicas, buscando combinar o esporte, a educação e a cultura em harmonia entre o corpo e a mente, com a excelência em si mesmo, aliando-os ao respeito e à alegria.

O Princípio Fundamental número 2, presente na Carta Olímpica (2004), define o Olimpismo como uma filosofia de vida, que exalta e combina, em um conjunto harmônico, as qualidades do corpo, a vontade e o espírito. Ao associar o esporte com a cultura e a educação, o Olimpismo propõe criar um estilo de vida baseado na alegria do esforço, o valor educativo do bom exemplo e o respeito pelos princípios éticos fundamentais universais. Defende, ainda, a formação de uma maneira pacífica, democrática, humanitária, cultural e 
ecológica por meio da prática esportiva. Mas para colocar ideias tão subjetivas em prática, o Comitê Olímpico Internacional propôs ‘traduzir’ a Filosofia Olímpica em valores: excelência, amizade e respeito (INTERNATIONAL OLYMPIC COMMITTEE, 2007a).

Nessa perspectiva, ressaltamos que o que faz dos Jogos e do Movimento Olímpico um sucesso não é apenas a prática esportiva e a sua tensão emocional, mas todo o repertório de valores que acompanham estes fenômenos (MORETTI e TAPETTI, 2007). Isso porque os elementos envolvidos nestes eventos, e no próprio Olimpismo, refletem, segundo Todt (2009), os valores do país sede e servem como propulsor para uma afirmação da identidade nacional, promovendo o turismo, o comércio e as ideologias políticas, combinando esta estrutura com as necessidades da indústria do entretenimento e inovações tecnológicas. Esses elementos também estão vinculados aos ideais olímpicos, propostos por Coubertin, assim como os símbolos olímpicos, fixados pela Carta Olímpica (INTERNATIONAL OLYMPIC COMMITTEE, 2007b).

\section{Brilhante civilização: 5000 anos de história chinesa}

O segmento 'Brilhante Civilização', parte do objeto desta análise, iniciou com a exibição de um vídeo artístico sobre a fabricação do papel, uma das grandes invenções chinesas. Nesse momento, uma tela de led em formato de pergaminho foi desenrolada no centro do estádio, exibindo imagens da arte chinesa. Podemos perceber bailarinos posicionados acima da tela, que foram entrando solenemente e que passaram a criar uma aquarela em uma lona, ao som do guqin, um dos mais antigos instrumentos de corda do mundo. No decorrer do vídeo, imagens de homens fabricando o papel mostravam movimentos de trabalho (o movimento de corte, o de passar o pincel, o de virar o papel e o de abrir o pergaminho), que são identificados posteriormente na coreografia desse segmento.

O movimento de corte (muito usado no corte de plantações de arroz, de onde era retirada a matéria-prima para a fabricação do papel) foi representado na coreografia pelo movimento das pernas, como cortes no ar com muitos entrelacés ${ }^{1}$ e ciseaux ${ }^{2}$.

\footnotetext{
${ }^{1}$ Palavra francesa que significa entrelaçados. Neste movimento as pernas se entrelaçam no ar.

2 Palavra francesa que significa tesoura. Neste movimento as pernas se abrem em movimento amplo de tesoura ou troca, realizado no ar.
} 
O movimento de passar o pincel foi observado ao entrar o primeiro bailarino no pergaminho que o percorreu como se indicasse que ali começava a pintura. Ao parar, viravase para o seu lado direito e executava com os braços o movimento exatamente igual ao original de pintar mostrado na projeção; posteriormente, ele assumia o papel do movimento e o corpo realmente passava a pintar o pergaminho.

O movimento de virar o papel foi representado nas cambalhotas e rolamentos; e o movimento de abrir o pergaminho, pelos developpés ${ }^{3}$, trocas de direção e de níveis e pelos deslocamentos do conjunto final. Esses bailarinos, atuando como pincéis através de seus movimentos, vestiam-se com um traje sóbrio, típico chinês, que continha uma linha horizontal de amarração, que, colocada uma em baixo da outra sobre o peito, acentuava a linha vertical, detalhe presente nos braços e nas pernas.

A cor escura do figurino, em contraste com o fundo claro do pergaminho, assegurava à platéia a percepção de que os movimentos dos corpos dos bailarinos formavam o desenho. Os movimentos eram fluidos e contínuos, sem interrupção abrupta. Mas, ao mesmo tempo, eram fortes. Era tamanha a fluidez e a velocidade dos deslocamentos dos corpos, que lançavam certa virilidade a eles, estando sempre em permanente busca do equilíbrio através de desequilíbrios. Para isso, mantinham a linha da cabeça baixa e as mãos próximas ao chão, pois eram delas que saíam as pinturas. Alternavam solos, duos e trios, transitando facilmente pelos três níveis: alto, médio e baixo. Numa demonstração de sincronismo, força e flexibilidade, no conjunto final iam mergulhando num mar laranja que foi tomando conta da tela, até que sobrava somente um bailarino, que terminava de desenhar, em movimentos circulares, com toda a amplitude de seu corpo, uma roda assimétrica, que representava o sol. Esse grupo de bailarinos era composto por homens e mulheres, mas não havia na coreografia uma definição de movimentos que os diferenciasse. A visão coreográfica era extremamente espacial, reforçada pelo ângulo da filmagem, sempre acima do nível dos bailarinos. Após a aquarela ficar pronta, composta de montanhas iluminadas pelo sol, a tela era erguida e retirada.

\footnotetext{
${ }^{3}$ Palavra francesa que significa desenvolvido. Neste movimento ocorre um desenrolar dos membros inferiores, onde um dos pés parte do chão e vai passando pelo membro inferior que está apoiado no chão (perna de sustentação) até chegar ao movimento fora do chão, realizando uma extensão do joelho, em diversas elevações e direções.
} 
Podemos dizer que aquilo que torna a representação passível de leitura e mobilização é o imaginário, que é histórico e datado, ou seja, em cada época os homens constroem representações para conferir sentido ao real. Essa construção de sentido é ampla, uma vez que se expressa por palavras/discursos/sons, imagens, materialidades e por práticas, ritos, performances. O imaginário comporta crenças, mitos, ideologias, conceitos, valores, é construtor de identidades e exclusões, hierarquiza, divide, aponta semelhanças e diferenças no social. Pesavento (2008) diz que é um saber-fazer que organiza o mundo, produzindo a coesão ou o conflito.

Na seqüência da coreografia apresentada no segmento analisado, artistas representando os 3000 Discípulos de Confúcio recitaram trechos dos Analectos: todos, nos quatro mares, podem ser considerados irmãos. A entrada foi realizada a passos largos e lentos, mostrando uma chegada firme, absoluta. Seguravam nas mãos o pergaminho, recolheramno e seguiram seu trajeto a passos pequenos e rápidos. Nessa parte, uma postura ereta foi adotada continuamente, com exceção das partes onde foram feitas as saudações, momento em que os bailarinos-atores se curvavam em reverência ao seu mestre, abrindo no chão o pergaminho. Foi visível o seu acatamento aos comandos dados; a crença passa ao movimento. Também foi interessante notar que todos eram homens, resquícios de uma comunidade ainda muito aquém dos direitos igualitários. Usavam uma espécie de túnica longa, bem rodada, com uma faixa na cintura, as mangas eram extremamente amplas e longas, o que fazia com que andassem sempre com os braços na altura do peitoral, seja quando abertos ou quando colocados à frente do corpo, encostando as mãos.

No figurino havia um detalhe nos dégradés das cores da roupa que chamava atenção para a amplitude dos tecidos: perto do tronco, tom cinza escuro, clareando até chegar ao branco neve nas pontas, tanto na saia quanto nas mangas. Os cabelos estavam presos em um coque, atravessados por uma vareta, de onde despontava um cone com penas claras, longas, que acrescentava mais ou menos um metro na altura dos bailarinos. Esse figurino nos remete ao contexto do período que queriam representar, a não ser pelo uso padronizado de tênis branco, que provavelmente não era a opção da época. O jogo de cores do figurino acentuou a dinâmica das caminhadas e ampliou todo o jogo de movimentação contralateral: o corpo ia para um lado e o movimento do tecido para o oposto. Em alguns momentos, a 
roda das saias se reunia pelos movimentos sincronizados de todos os bailarinos, formando um plano só, mesclando um mar de tecido, braços e cabeças, assemelhando-se a flores num amplo jardim. Essa imagem pode ser contrastada, em um momento, pelo choque entre o que ela nos remete e o movimento que realmente estava sendo executado pelos bailarinos-atores. Esse militarismo físico que, ao mesmo tempo, nos passa a sensação de serem extremamente secos e duros em sua colocação cênica, mas também nos sensibiliza em razão das qualidades das estruturas espaciais perfeitamente formadas num sincronismo completo, executado por uma massa de trabalhadores do movimento.

O efeito da música, por sua vez, não poderia ser artificialmente destacado do restante da performance. A música, para Pavis (2005), preenche a função de criar uma atmosfera introduzida pelo tema musical. Esta atmosfera musical auxilia a situar o lugar da ação, torna uma situação reconhecível e pontua a ação ao produzir pausas. Criam-se, pela música, contrapontos que geram uma sucessão de nuances à cena, onde os ritmos globais e específicos dão a duração subjetiva da representação. Assim, é essa variação dos ritmos dos acontecimentos gerais e pontuais, reforçados pela imagem em movimento, que transporta o espectador ao sistema que torna o desenrolar do espetáculo um quadro rítmico.

As movimentações descritas vão além da demonstração de costumes ou de contar histórias; são uma experiência visual e estética que aguçam a imaginação do espectador a deixar-se levar por aquele movimento onde ele estiver, conectam e sensibilizam emoções.

Essa ideia nos faz compreender e analisar a "Cerimônia de Abertura dos Jogos Olímpicos de Pequim/2008" sob a perspectiva do programa artístico e dos valores olímpicos de excelência, respeito e amizade, alinhando-nos ao pensamento contemporâneo estético de que a significação depende do contexto histórico em que se realiza.

Para Paviani (2003), não podemos ignorar o potencial ideológico trazido pelos meios de comunicação em suas transmissões, tão pouco devemos minimizar sua atuação na função de comunicação às grandes massas. Devemos, isto sim, identificar o emprego estético comercial potencializado sobre eles. Conforme o autor, a dimensão estética dos meios de comunicação na sociedade de massa é que nos dá a definição entre arte e comunicação, em parte essa diferença pode ser traduzida como o equilíbrio entre o estético e o semântico, o social e o semiótico. Considera que quanto maior for o público 
atingido, maior incorporação dos valores repassados será efetivada, pois a legitimação das manifestações culturais passa por uma série de elementos constitutivos, que vão além da dimensão dos modelos de cultura. Segundo Müller (2004), é através da mídia que a Nação Olímpica, na abertura dos Jogos, se torna o símbolo do conceito olímpico de universalismo. As grandes conquistas de seus participantes simbolizam a luta e as vitórias de toda a humanidade. Se este símbolo for igualmente associado ao fair play e ao respeito mútuo, os atletas apresentam um exemplo bem sucedido de coexistência entre povos em situações críticas. O caráter de cerimônia que acompanha os Jogos Olímpicos concede a estas conquistas particular significado.

Sob esta perspectiva faz sentido, então, identificar valores em uma representação, através da comunicação do corpo, pelo meio da coreografia, pelo fim do espetáculo. Para entender o corpo como agente comunicativo, é necessário definir o artista cênico, que será o meio desta transmissão. Para Strazzacappa (1998), ele traz consigo, em seu corpo, o resultado de sua obra, é ao mesmo tempo agente (técnica) e produto (arte). Essa conscientização traz a assertiva de que o trabalho corporal interfere no resultado cênico, mesmo quando este é apoiado por recursos exteriores a ele. A técnica corporal, a qual a autora se refere, diz respeito àquela criada especificamente para a cena, para o performer, termo que define aquele que tem no corpo a sua arte, que realiza uma apresentação, uma performance, concretizando em si a transdisciplinaridade do espetáculo.

\section{Era gloriosa: a conquista da China moderna}

No segundo ato, o chão do estádio se abriu e blocos brancos surgiram representando os tipos móveis de impressão, a terceira das grandes invenções chinesas. Estes blocos se moviam para formar três variantes do caractere 和 (he - harmonia) e a Grande Muralha da China. Ao final do segmento, revelou-se que os movimentos dos blocos eram controlados por 897 pessoas. Pavis (2005) afirma que a experiência espacial varia de acordo com o entendimento do lugar teatral, o prédio onde ocorre a ação, do espaço cênico onde se dá propriamente a encenação e do espaço liminar que marca a separação da evolução da cena com a platéia, traçando mentalmente a atenção do espectador. 
A captação sintética de conjuntos simultâneos e o metatexto da encenação, algo que ocorre muito nas Cerimônias de Abertura dos Jogos Olímpicos, devido à ampla continuidade e multiplicidade dos acontecimentos e dos desdobramentos deles vindos, são tratados por Pavis (2005) obedecendo à mesma lógica de estruturação em conjuntos amplos e claros (a experiência analítica do espetáculo é sempre vertical e sintética e não puramente linear e fragmentária). O espectador percebe todos os elementos da encenação como totalidades temporais, os quais coincidem e se manifestam em signos cênicos e sintéticos. Em suma, ele não despedaça a representação, mas se serve de largas fatias de espaço temporais, no interior das quais o sentido forma um conjunto coerente. Tal noção continua útil para reagrupar sistematicamente as propriedades da representação, cujo conjunto forma um sistema lógico. Lembrando que o metatexto não é propriedade do encenador, mas, sim, o sistema estrutural evolutivo que serve de esquema diretor e de síntese para o espectador.

O segmento aqui analisado trouxe também para o estádio a Ópera de Pequim e uma performance com bonecos, seguido da representação da Rota da Seda e da Rota Marítima usada por Zheng He. Essa parte representou a quarta e última grande invenção chinesa apresentada na cerimônia: a bússola. Uma das mais antigas óperas chinesas, a de Kunqu, foi apresentada. Torres vermelhas e laranja emergiram, enquanto dançarinas, representando as dinastias que governaram o país passaram pelo palco. A representação das caravelas que faziam as rotas foi grandiosa. Os performers moviam-se com a precisão necessária para dar forma e sentido aos mastros das embarcações formando, ao final, um único barco que ocupou todo o palco. O pianista Lang Lang apresentou-se acompanhado de Li Muzi, uma menina de cinco anos. Ao redor do pianista, dançarinos com lâmpadas presas às roupas representaram a China Moderna, formando o desenho de um pássaro e recriando a estrutura do Estádio Olímpico.

Segundo Pavis (2005), o limite do figurino não é o corpo. O impacto que o figurino rege sobre a impressão que se tem sobre a encenação constitui, muitas vezes, o primeiro sinal que o espectador tem sobre a encenação. Para a autora o figurino também caracteriza o meio social, a época, o estilo e a localização da ação. Ele relaciona-se com o corpo, assim como o corpo relaciona-se com ele, assim como se relaciona com o cenário, limitando ou ampliando o corpo em seu lugar. 
A partir de um olhar no qual transcende a superficialidade, percebemos a arte como um canal de comunicação. Este canal torna-se um objeto de prazer estético, revelado através da grandeza do sensível, comunicando sentimentos, ideais, remetendo a diferentes atmosferas temporais e meios sociais. (PAVIANI, 2003).

Para Pesavento (2008) as representações envolvem os processos de percepção, identificação, reconhecimento, classificação, legitimação e exclusão, mostrando a receptividade social, sua força e seu poder de mobilização e legitimação.

Os acrobatas desse trecho do espetáculo faziam parte de uma proposta estética que iniciava pelos movimentos de ondas e que se transformava aos poucos em uma mandala da pomba da paz. Passavam para reprodução de uma determinada estrutura que remeteu o espectador ao próprio estádio onde ocorreu a cerimônia, fechando pelo figurino que, todo iluminado, colocou-o diante de uma imensa massa de luz, de tons esverdeados e fluorescentes. Pavis (2005) refere que a iluminação combina um sistema de sensações, dando uma dramaturgia à luz, compreendendo assim que ela influi sobre todos os componentes do espetáculo.

Dois mil e oito mestres de Tai Chi Chuan apresentaram-se em um cenário de sala de aula, representando as relações homem-natureza. Nesse momento, crianças no centro do estádio, passaram a pintar sobre o painel antes utilizado, simbolizando a proteção ao meio ambiente e o respeito à natureza. Os mestres desenvolveram uma coreografia com os movimentos de sua arte marcial. Em seguida, realizaram uma evolução espacial, feita através de uma corrida e se retiraram do palco, enquanto as crianças assistiam a uma projeção de pássaros no círculo superior do estádio e o painel era içado novamente, revelando a pintura pronta.

Constatamos, nesse trecho, referência ao valor olímpico respeito. Valor aqui representado pelo símbolo do fair play idealizado pelo Olimpismo, vinculando a promoção e divulgação do esporte e da cultura à preocupação com o meio ambiente, com a educação ambiental e com a formação de uma consciência ecológica (MIRANDA, 1999). Como bem aponta Meinberg (1997 apud BONZO e BANDEIRA, 2007) este é o desafio atual: basear a ética não somente nas relações homem a homem por meio de uma moral esportiva simbolizada pelo fair play, mas igualmente em posturas éticas do homem com ele mesmo e com o mundo. 
No caso da Cerimônia de Pequim/2008, podemos dizer, ainda, que o uso intenso de grupos coreográficos pode relacionar-se com a expectativa de Garaudy (1980), ao afirmar que a dança tem por objeto captar aquela força viva, que nasce dos esforços ritmados do grupo, que assim se afirma e constitui a unidade do homem e de seu meio, do indivíduo e do grupo, construindo uma relação de respeito.

O último momento desse segmento se iniciou com a chegada de astronautas simbolizando a exploração espacial chinesa, que levou Yang Liwei ao espaço em 2006. Do centro do estádio surgiu uma alegoria representando o globo terrestre. Na estrutura de dezesseis toneladas foram apresentadas projeções da Terra e do Sol. Nesses globos, atores-bailarinos se deslocavam. Nesse momento, os cantores Liu Huan e Sarah Brightman apresentaram-se para a execução da canção oficial dos Jogos: "You and Me". Pessoas trazendo guarda-chuvas estampados com imagens de crianças de todas as nacionalidades entraram no estádio, ao mesmo tempo em que fogos de artifício no formato de rostos sorridentes eram lançados. A parte artística encerrou-se com um show pirotécnico e com a passagem de artistas representando as cinqüenta e seis etnias do país.

Percebemos, também, durante essa movimentação coreográfica, uma forte relação com o valor olímpico da amizade. Com efeito, esse valor traz em si a tentativa de encorajar as pessoas a considerarem o esporte como uma ferramenta de mútuo entendimento entre os povos de todo o mundo, na busca de inspirar a humanidade a superar as diferenças políticas, econômicas, de gênero, de raça ou de religião.

Se um dos principais objetivos da Cerimônia de Abertura dos Jogos Olímpicos é transmitir a ideia de que o Respeito engloba comportar-se eticamente perante si e a sociedade; a Excelência, de difundir a superação do indivíduo, combinando corpo, mente e espírito forte; e, a Amizade, de superar diferenças; é notória a presença desses valores no espetáculo cênico e nas movimentações coreográficas analisadas.

\section{Considerações Finais}

Consideramos que o espetáculo cênico e as movimentações coreográficas da "Cerimônia de Abertura dos Jogos Olímpicos de Pequim/2008" estão vinculados à ideia de transmissão 
dos valores olímpicos Excelência, Respeito e Amizade. Considerando as análises realizadas, acreditamos que ocorreu a efetiva incorporação dos valores investigados, pois a legitimação das manifestações culturais passa por uma série de elementos constitutivos, que vão além da dimensão dos modelos de cultura, habitando paradigmas ideológicos.

Um ponto importante que nos levou a perceber a presença dos valores olímpicos na análise da Cerimônia foi a estética dos conjuntos que permeou todo o espetáculo cênico e as movimentações coreográficas. O que vem a confirmar o proposto pelo Código de Conduta do Movimento Olímpico, que busca nortear as atitudes e ações de todos os envolvidos nas atividades olímpicas, fazendo das alianças com as representações culturais e com as artes uma forma de promover esses valores.

Aestética desse espetáculo esteve fortemente ligada aos conceitos de harmonia, unidade, ordem e simetria. A artisticidade dos signos foi dada por diferentes programas poéticos, determinados por ambientes sociais e culturais reproduzidos no espetáculo cênico. Estes espaços foram bem específicos da cultura do país sede, porém o espetáculo cênico e as movimentações coreográficas foram destinados à normatização do sentimento, ampliando nossa faculdade de perceber e adaptá-los para nossa cultura e nossas referências.

O espetáculo cênico passou a ideia de uma crença coletiva, de duração estável, que influencia e dá significado às relações sociais e culturais; estas concepções, estes sentimentos que interpretam nossa vida cotidiana, são os valores. Constatamos assim, que as movimentações coreográficas passaram o conceito de comportamento ético perante si mesmo e à sociedade, do país anfitrião e dos convidados, difundiram a superação do indivíduo, combinando corpo, mente e espírito forte e, pelo menos naquele momento, superaram as diferenças políticas, econômicas, de gênero, de raça e de religião, identificando e traduzindo de uma maneira corporal, visual e musical os valores Respeito, Excelência e Amizade.

Agora nos resta esperar ansiosamente pela Cerimônia de Abertura dos Jogos Olímpicos que ocorrerá no Brasil em 2016, para saber se esse evento conseguirá transmitir, assim como o fez a Cerimônia analisada, dentro da estrutura proposta pelo Comitê Olímpico Internacional, os valores olímpicos universais e os da nação brasileira. 


\section{Referências}

BAUER, M. W.; Gaskell, G.; tradução Guareschi, P. A. (2008). Pesquisa qualitativa com texto, imagem e som: um manual prático. Petrópolis, RJ: Vozes, 2002.

BONZO, Carolina; BANDEIRA, Marília. Olimpismo, Educação e Meio Ambiente. In: RUBIO, Kátia (org.) Educação Olímpica e Responsabilidade Social. São Paulo: Casa do Psicólogo, 2007.

DACOSTA, Lamartine. Educação Olímpica como metalinguagem axiológica: revisões pedagógicas e filosóficas de experiências internacionais e brasileiras. In: REPPOLD FILHO, Alberto R. et al. (org). Olimpismo e Educação Olímpica no Brasil. Porto Alegre: Editora da UFRGS, 2009. p. 17-28.

GARAUDY, Roger. Dançar a vida. Rio de Janeiro: Nova Fronteira, 1980.

GARCIA, Beatriz. The Cultural Dimension of Olympic Games: Ceremonies and Cultural Olympiads as Platforms for Sustainable Cultural Policy. In: PEÑA, Emilio et al. (eds.). An Olympic Mosaic: Multidisciplinary Research and Dissemination of Olympic Studies - CEOUAB: 20 years. Barcelona: Direcció d'Imatge I Serveis Editorial, 2011. 153-163.

INTERNATIONAL OLYMPIC COMMITTEE. Olympic Charter. Lausanne: International Olympic Committee, 2004.

INTERNATIONAL OLYMPIC COMMITTEE. The Olympic Symbols. 2 ed. Lausanne, 2007b.

INTERNATIONAL OLYMPIC COMMITTEE. Opening ceremony of the Games of the Olympiad. Fact sheet. Lausanne: International Olympic Committee 2007a.

LOIZOS, Peter. Vídeo, Filme e Fotografias como Documentos de Pesquisa. In: BAUER, Martin W; GASKELL, George (org). Pesquisa Qualitativa com Texto, Imagem e Som. Um manual prático. Petrópolis, RJ: Vozes, 2002. p. 137 - 155.

MAUSS, Marcel. "As Técnicas Corporais". Sociologia e Antropologia. vol. 2. São Paulo: EPU/EDUSP, 1974.

MORAGAS, Miquel de; MACLOON, John; LLINÉS, Montserrat. Olympic Ceremonies: HistoricalContinuityandCulturalExchange. Lausanne:InternationalOlympicCommittee,1996. <http://doc.rero.ch/Im.php?url=1000,10,38,20100507114927-TX/IOC_Symposium_1995.pdf.> 
MORETTI, Alexandre R.; TAPETTI, Carlos H. Educação Olímpica formal, não formal e informal. In: RUBIO, Kátia (org). Educação Olímpica e responsabilidade social. São Paulo: Casa do Psicólogo, 2007. p. 71-85.

MÜLLER, N. Olympic Education: University lecture on the Olympics. Barcelona: Centre d'Etudies Olimpics (UAB). International Chair in Olympism (IOC - UAB), 2004. <http://olympicsstudies.uab.es/lecture/web/pdf/muller.pdf>.

PALUDO, Luciana. Temporalidades distintas no continuum da existência. Revista da Fundarte. v. 9, 2009. p. 28-34.

PAVIANI, Jayme. A arte na era da indústria cultural. Estética mínima: notas sobre arte e literatura. 2.ed. Porto Alegre: EDIPUCRS, 2003.

PAVIS, Patrice. A análise dos espetáculos. São Paulo: Perspectiva, 2005.

PESAVENTO, Sandra Jatahy. História \& História Cultural. Belo Horizonte: Autêntica, 2008.

RUBIO, Katia. Alteridade e cidadania como caminhos para a compreensão da diversidade e do multiculturalismo na Educação Olímpica. In: REPPOLD FILHO, Alberto R. et al. (org). Olimpismo e Educação Olímpica no Brasil. Porto Alegre: Editora da UFRGS, 2009. p. 89-96.

STRAZZACAPPA, Márcia. As técnicas corporais e a cena. In: GREINER, Christine; BIÃO, Armindo (org). Etnocenologia, textos selecionados. São Paulo: Annablume, 1998. p. 163-168.

THE OFFICIAL WEBSITE OF THE BEIJING 2008 OLYMPIC GAMES. Disponível em: http://en.beijing2008.cn. Acesso em 20/08/2010.

TODT, Nelson Schneider. As Cerimônias de Abertura dos Jogos Olímpicos de verão, sob uma perspectiva da educação olímpica. In: REPPOLD FILHO, Alberto R. et al. (org). Olimpismo e educação olímpica no Brasil. Porto Alegre: Editora da UFRGS, 2009. p. $111-122$. 
“OLYMPIC GAMES OPENING CEREMONY OF BEIJING/2008” AND THE RELATION WITH OLYMPIC VALUES

\begin{abstract}
Pierre de Coubertin, founder of the Olympic Games of the Modern Era, considered the Olympic Games Opening Ceremony a means to illustrate the olympic values. The olympic values must be represented in the Olympic Games Opening Ceremonies by symbols and rituals and transmitted through choreographic, theatrical and cultural representations. The aim of this study was analyze if Olympic Games Opening Ceremony of Beijing/2008 was effective in the transmission of the olympic values Respect, Excellence and Friendship. Through a video analysis of the Ceremony it was possible to verify that the performances and the choreographies helped in identifying the olympic values Respect, Excellence and Friendship.

Keywords: Olympic Games. Olympic Values. Dancing.

\section{EL ESPECTÁCULO ESCÉNICO “CEREMONIA DE APERTURA DE LOS JUEGOS OLÍMPICOS DE PEQUÍN/2008" Y SU RELACIÓN CON LOS VALORES OLÍMPICOS RESUMEN}

RESUMEN: Pierre de Coubertin, idealizador de los Juegos Olímpicos de la Era Moderna, consideraba la Ceremonia de Apertura de los Juegos un medio para ilustrar los valores olímpicos. Los valores olímpicos deben ser representados en las Ceremonias de Apertura por símbolos y ritos, transmitidos en la forma de representaciones coreográficas, dramaturgicas y culturales. El objetivo de ese estudio fue analizar si la Ceremonia de Apertura de los Juegos Olímpicos de Pequín/2008 fue efectiva en la transmisión de los valores olímpicos Respeto, Excelencia y Amistad. A través de la analice del vídeo de la Ceremonia fue verificado que el espectáculo escénico auxilió en la transmisión de los valores olímpicos Respeto, Excelencia y Amistad.

Palabras-clave: Ceremonias Olímpicas. Valores Olímpicos. Baile. 